\title{
Nicotine upregulates ACE2 expression and increases competence for SARS-CoV-2 in human pneumocytes
}

\author{
Fabrizio Maggi ${ }^{1,2}$, Alfredo Rosellini ${ }^{3}$, Pietro Giorgio Spezia ${ }^{4}$, Daniele Focosi ${ }^{5}$, \\ Lisa Macera ${ }^{3,4}$, Michele Lai $\mathbb{1}^{4}$, Mauro Pistello ${ }^{3,4}$, Antonio de lure $\mathbb{1}^{6}$, \\ Carlo Tomino ${ }^{7}$, Stefano Bonassi, ${ }^{8,9}$ and Patrizia Russo 8,9
}

Affiliations: ${ }^{1}$ Dept of Medicine and Surgery, University of Insubria, Varese, Italy. ${ }^{2}$ Laboratory of Clinical Microbiology, ASST dei Sette Laghi, Varese, Italy. ${ }^{3}$ Virology Division, Pisa University Hospital, Pisa, Italy. ${ }^{4}$ Dept of Translational Research, University of Pisa, Pisa, Italy. ${ }^{5}$ North-Western Tuscany Blood Bank, Pisa University Hospital, Pisa, Italy. ${ }^{6}$ Experimental Neurophysiology, IRCSS San Raffaele Pisana, Rome, Italy. ${ }^{7}$ Scientific Direction, IRCSS San Raffaele Pisana, Rome, Italy. ${ }^{8}$ Clinical and Molecular Epidemiology, IRCSS San Raffaele Pisana, Rome, Italy. ${ }^{9}$ Dept of Human Sciences and Quality of Life Promotion, San Raffaele University, Rome, Italy.

Correspondence: Patrizia Russo, Clinical and Molecular Epidemiology, IRCSS San Raffaele Pisana, Via di Val Cannuta, 247, I-00166 Rome, Italy. E-mail: patrizia.russoduniroma5.it

ABSTRACT The coronavirus disease 2019 (COVID-19) pandemic has a variable degree of severity according to underlying comorbidities and life-style. Several research groups have reported an association between cigarette smoking and increased severity of COVID-19. The exact mechanism of action is largely unclear.

We exposed low angiotensin-converting enzyme 2 (ACE2)-expressing human pulmonary adenocarcinoma A549 epithelial cells to nicotine and assessed ACE2 expression at different times. We further used the nicotine-exposed cells in a virus neutralisation assay.

Nicotine exposure induces rapid and long-lasting increases in gene and protein expression of the severe acute respiratory syndrome coronavirus 2 (SARS-CoV-2) receptor ACE2, which in turn translates into increased competence for SARS-CoV-2 replication and cytopathic effect.

These findings show that nicotine worsens SARS-CoV-2 pulmonary infection and have implications for public health policies.

@ERSpublications

Nicotine, the psychotropic substance of tobacco, in human lung adenocarcinoma A549 cells, induces increased gene and protein expression of the \#SARSCoV2 receptor ACE2, which in turn translates into high SARS-CoV-2 replication and cytopathic effect https://bit.ly/36njkA9

Cite this article as: Maggi F, Rosellini A, Spezia PG, et al. Nicotine upregulates ACE2 expression and increases competence for SARS-CoV-2 in human pneumocytes. ERJ Open Res 2021; 7: 00713-2020 [https://doi.org/10.1183/23120541.00713-2020].

This article has supplementary material available from openres.ersjournals.com

Received: 30 Sept 2020 | Accepted: 24 Jan 2021

Copyright $\odot$ The authors 2021. This version is distributed under the terms of the Creative Commons Attribution NonCommercial Licence 4.0. For commercial reproduction rights and permissions contact permissions@ersnet.org 


\section{Introduction}

As of September 28, the ongoing coronavirus disease 2019 (COVID-19) pandemic has caused more than 32 million cases and nearly one million deaths worldwide.

In addition to laboratory markers, several underlying clinical risk factors for COVID-19 severity have been identified [1], such as age, diabetes mellitus, systemic arterial hypertension, cardiovascular diseases, chronic obstructive pulmonary disease, chronic liver disease and cancer [2, 3]. All these risk factors are unmodifiable. Among behavioural, modifiable risk factors, the attendance of crowded places without protective equipment is among the most largely accepted. On the contrary, the effect of smoking tobacco (cigarettes or water pipe), e-cigarettes or nicotine replacement therapy (NRT) is still debated. Several authors initially reported a protective role for nicotine, based on the lower prevalence of current smokers among COVID-19 patients [4-6], supported by in silico studies on the interaction between the severe acute respiratory syndrome coronavirus 2 (SARS-CoV-2) spike protein receptor-binding domain and nicotinic receptor (nAChR) sub-type $\alpha 9$ and/or $\alpha 7[7,8]$ or by speculations on the therapeutic use of nicotine agonists [9-11] in the quest for better therapeutics. Also, a negative correlation between the age-standardised prevalence of tobacco smoking and the attack rate [12] and mortality of COVID-19 was reported [13].

Smoking, apart from being a risk factor for tobacco-related diseases [14], can be a direct risk factor for COVID-19 transmission by producing exhaled smoke, coughing or sneezing, and aerosols containing SARS-CoV-2 in the surroundings and contaminating surfaces [15], and has been reported to double severity [16] and mortality [17] in patients affected by COVID-19. Extensive evidence shows the negative effects of exposure to nicotine [18, 19]. Indeed, nicotine is identified as an inducer of angiotensinconverting enzyme 2 (ACE2) overexpression, the only recognised receptor of SARS-CoV-2 [20], in the lower airways of current smokers and COPD patients [10, 21-24], suggesting that higher levels of ACE2 (i.e. induced by nicotine exposure) implies more gateways for the SARS-CoV-2 virus. Moreover, it is possible to hypothesise that SARS-CoV-2 entry and replication may be facilitated or induced through mechanisms related to nAChR-mediated pathways, all converging to ACE2 regulation and signalling [14, 24]. Additionally, nicotine exposure induces a pro-thrombotic state via stimulation of tissue factor expression both in endothelial cells and smooth muscle cells [25] as well as neo-angiogenesis [26] and, finally, elevated serum cotinine levels, the metabolite of nicotine, are associated with left atrial abnormalities, a possible mechanism for increased risk of cardiovascular diseases (CVD) [27]. Importantly, post mortem examinations of people who died with COVID-19 revealed widespread vascular abnormalities including thrombosis, microangiopathy, and a high degree of angiogenesis [28]. Taking into consideration all the above findings and the observation that nicotine potentiates viral infections [29], it is unlikely that smoking or vaping may offer therapeutic benefits in COVID-19.

Nevertheless, the underlying mechanism of action through which nicotine could facilitate SARS-CoV-2 infection remains largely unknown. Evidence on the regulation of ACE2 in the lungs after exposure to nicotine is still inconclusive, with evidence both for down-regulated ACE2 axis [30], in bronchial epithelial cells [31] and for enhanced ACE2 expression in lung tissue of COPD patients, at a lower extent in healthy smokers, and absent in healthy non-smoking individuals [22, 32-34].

It is important to remark that, until now, there is no indication that nicotine prevents the entry of SARS-CoV-2 into host cells or that it protects cells from the severity of SARS-CoV-2 infection, for this reason, we planned studies where cells were infected with SARS-CoV-2 in the presence or absence of nicotine.

We investigated here whether ACE2 is overexpressed in pneumocytes after exposure to nicotine, and if this leads in turn to increased SARS-CoV-2 replication and cytopathic effect.

\section{Materials and methods}

\section{Cells exposure to nicotine}

Nicotine (Sigma-Aldrich, St. Louis, MI, USA) was assayed using in vitro experiments for its ability to stimulate ACE2 expression in A549 cells. The A549 type II pulmonary adenocarcinoma cell line (isolated in 1973, [35]) was selected because of the low-levels of ACE2 expression. A549 cells require transgenic ACE2 expression to be used in plaque reduction neutralisation test (PRNT), thus it is the ideal cell line to measure ACE2 up-regulations.

\section{In vitro cytotoxicity of nicotine and cell viability assay}

For determining the optimal experimental dose of nicotine and for evaluating the proliferation of the cells under nicotine treatment, the viability of the pulmonary A549 cells was assessed. Cytotoxicity was determined by the alamarBlue assay (Thermo Fisher Scientific, Waltham, MA, USA). 
Anchorage-independent soft-agar colony formation and cell migration

Anchorage-independent growth was assayed by the ability of cells to form colonies in soft agar. Colonies were visualised and quantified under a microscope after 18 days of cultivation, with or without nicotine at concentrations of 0.1 or $0.01 \mu \mathrm{M}$, replaced every $48 \mathrm{~h}$. At the end of the incubation period, colonies were stained with $0.01 \%$ crystal violet in $70 \%$ ethanol, then photographed and counted under an inverted microscope.

CytoSelect 24-well Cell Migration Assay $(8 \mu \mathrm{m}$, Fluorometric format) was obtained by Cell Biolabs (CBA-101-C; San Diego, CA, USA), and experiments were performed according to the manufacture's protocol.

\section{Real-time PCR for ACE2 mRNA}

Total RNA was extracted from A549 cells by using TRIzol reagent (Invitrogen GmbH, Karlsruhe, Germany) and then used for quantitating ACE2 and $\beta$-actin gene RNAs using real-time PCR assays. The assays were carried out on a Bio-Rad CFX96 real-time PCR system (Bio-Rad Laboratories, Hercules, CA, USA) using commercial one-step Quantitect SYBR Green RT-PCR kit (Qiagen Inc., Valencia, CA, USA) with the following primer pairs: i) ACE2 forward: 5'- GGGATCAGAGATCGGAAGAAGAAA -3' and ACE2 backward: 5'-AGGAGGTCTGAACATCATCAGTG-3'; ii) $\beta$-actin forward: $5^{\prime}$-AAGGAGAAGCT GTGCTACGTC-3' and $\beta$-actin backward: 5'-AGACAGCACTGTGTTGGCGTA-3'. The assays were performed using a previously standardised thermal programme $\left(50.0^{\circ} \mathrm{C}\right.$ for $30 \mathrm{~min}, 95^{\circ} \mathrm{C}$ for $15 \mathrm{~min}$, 35 cycles of $15 \mathrm{~s}$ at $94.0^{\circ} \mathrm{C}, 60^{\circ} \mathrm{C}$ for $30 \mathrm{~s}$, and $72^{\circ} \mathrm{C}$ for $30 \mathrm{~s}$ ). Melting curves were produced by plotting the fluorescence intensity against the temperature as the temperature was increased from 65.0 to $95.0^{\circ} \mathrm{C}$ at $0.5^{\circ} \mathrm{C} \cdot \mathrm{s}^{-1}$. All samples were amplified in triplicate and negative PCR controls with no RNA template was included in each round of tests. Bio-Rad CFX Maestro 1.1 software was used to analyse the data (Bio-Rad Laboratories, Hercules, CA, USA). Differences in ACE2 expression were represented as the fold change in gene expression using the $2^{-\triangle \Delta C T}$ method. The housekeeping gene $\beta$-actin was used as the internal control for normalisation following preliminary experiments with nicotine and throughout the study was found not to be appreciably modulated.

\section{ACE2 protein detection}

ACE2 was measured with the Human ACE2 ELISA Kit ab235649 (www.abcam.com/human-ace2-elisa-kitab235649.html; Abcam, Cambridge, UK) according to manufacturer's instructions. Cells were treated with nicotine at $0.01 \mu \mathrm{M}$ for $1 \mathrm{~h}$ or at $0.1 \mu \mathrm{M}$ for $1 \mathrm{~h}, 24 \mathrm{~h}$, or $48 \mathrm{~h}$.

\section{Western blotting}

Cells were treated with nicotine at $0.1 \mu \mathrm{M}$ for $1 \mathrm{~h}$ or $24 \mathrm{~h}$. The ACE2 protein was detected by a mouse anti-ACE2 monoclonal antibody raised against amino acids 631-805 of ACE2 of human origin (ACE2 (E-11): sc-390851; Santa Cruz Biotechnology Incorporation, Dallas, TX, USA) or with anti- $\alpha 7-n A C h R$ NBP1-52375 (Novus Biological, Cambridge, UK), $\beta$-actin (1:2500, ab20272, Abcam). Membranes were incubated with Horseradish peroxidase-labelled conjugated secondary antibody corresponding to the primary antibody in the blocking buffer for $1 \mathrm{~h}$ at room temperature. An enhanced chemiluminescence kit (Western blot detection reagent, GE Healthcare, Amersham, UK) was used for the detection of recognised proteins. Densitometric analysis for quantification of the relative level of protein expression was performed using Amersham Image Quant800 (GE Healthcare) with software ImageQuant TL 7.0.

\section{SARS-CoV-2 culture}

As inoculum was used a SARS-CoV-2-positive cell supernatant. The cell supernatant, obtained by infecting Vero E6 cells with a nasopharyngeal swab of a patient with SARS-CoV-2 infection, contained 2000 tissue culture infectious dose $50\left(\right.$ TCID $\left._{50}\right)$, as estimated by endpoint titration.

Adherent A549 cell lines, grown in appropriate conditions of temperature and medium supplemented with heat-inactivated fetal bovine serum (FBS) and antibiotics/antimycotics, were exposed to the viral inoculum $(0.5 \mathrm{~mL})$ in the form of traditional culture when cell monolayers were less than 2 days old. After infection, the inoculum was removed, the monolayers rinsed three times with sterile phosphate-buffered saline (PBS), and $3 \mathrm{~mL}$ of the appropriate culture medium was added. All culture plates were incubated in a humidified $37^{\circ} \mathrm{C}$ incubator in an atmosphere of $5 \% \mathrm{CO}_{2}$. Cells were monitored daily for the development of cytopathic effects (CPE). After 3 days, $400 \mu \mathrm{L}$ of cell supernatant was used for total nucleic acid extraction for SARS-CoV-2 RNA testing. Negative control samples were supernatants obtained from A549 cells not infected with SARS-CoV-2. 
SARS-CoV-2 immunofluorescence assay

The presence of SARS-CoV-2 antigens in A549 infected cells was evaluated by indirect immunofluorescence using polyclonal antibodies directed against $\mathrm{N}$ and S proteins of SARS-CoV-2 (Sino Biological, Beijing, China). For the immunofluorescence assay, the cells grown in an 8-well chamber slide were rinsed twice with PBS, fixed in methanol solution at room temperature for $30 \mathrm{~min}$, washed three times with PBS, and then incubated with the specific anti-SARS-CoV-2 antibodies (diluted 1:60 in PBS) for $1 \mathrm{~h}$ at $37^{\circ} \mathrm{C}$. After three washes with PBS, the secondary antibody consisted of fluorescein isothiocyanate (FITC)-conjugated anti-rabbit IgG (diluted 1:1000 in PBS; Sigma, St. Louis, MI, USA) was added for $1 \mathrm{~h}$ at $37^{\circ} \mathrm{C}$. After three final washings, drying, and mounting, the slides were observed under a fluorescence microscope.

\section{SARS-CoV-2 RNA detection}

SARS-CoV-2 genome was detected by extracting RNA from $400 \mathrm{~mL}$ of cell supernatant using the Nimbus platform (Hamilton, Reno, NV, USA). After extraction, viral RNA was amplified by using the Allplex 2019-nCoV assay (Seegene, Seoul, South Korea) on the CFX96 instrument (Bio-Rad, Hercules, CA, USA), according to the manufacturer's instructions. The real-time Allplex 2019-nCoV assay simultaneously detects the $N$ gene, the $E$ gene, and the $R d R P$ gene of the SARS-CoV-2 genome. The cycle threshold (Ct) value was recorded for each of the three genes. Samples were considered positive when a PCR signal was detected at $\mathrm{C}_{\mathrm{t}}<40$ for any gene.

\section{Results}

\section{Nicotine stimulates the expression of the ACE2 gene}

In all experiments, A549 cell lines were treated for $24 \mathrm{~h}$ with $0.1 \mu \mathrm{M}$ of nicotine and then evaluated for ACE2 mRNA expression by reverse transcription real-time PCR. This timing was selected in previous experiments because it did not induce cytotoxicity on A549 cells (figure 1) but induced the highest level of ACE2 mRNA stimulation for all the nicotine concentrations investigated over the $48 \mathrm{~h}$ of incubation that were explored (figure 2). The negative control was cell cultures exposed to the diluent alone in which the nicotine was solubilised (e.g. $1 \mu \mathrm{L}$ ethanol in $1 \mathrm{~mL}$ complete DMEM). As shown in figure 2, nicotine added at three different doses produced a marked increase (nicotine dose: $0.1 \mu \mathrm{M}$ ), moderate increase (nicotine dose: $0.01 \mu \mathrm{M}$ ), or no detectable effect (nicotine dose: $10 \mu \mathrm{M}$ ) on expression levels of the ACE2 gene relative to the levels found in the negative control cultures. The increase in the gene expression peaked after $24 \mathrm{~h}$ of exposure and then declined at $48 \mathrm{~h}$.

Nicotine stimulates the secretion of ACE2 protein and induces cell proliferation and migration In these experiments, we measured the quantitative levels of ACE2 protein in extracts of A549 cell lines exposed to nicotine by using Western blot analysis and a sandwich ELISA. As shown in figure 3, results obtained by both methods revealed that the treatment with nicotine-induced levels of ACE2 protein was greatly enhanced in comparison to negative controls. HeLa cells are negative controls since according to ZHOU et al. [36] do not express ACE2 and consequently are not infected by SARS-CoV-2. The increase in the protein expression peaked after $24 \mathrm{~h}$ of exposure and then declined at $48 \mathrm{~h}$ as observed for gene

FIGURE 1 Cytotoxicity of nicotine on A549 cell cultures.

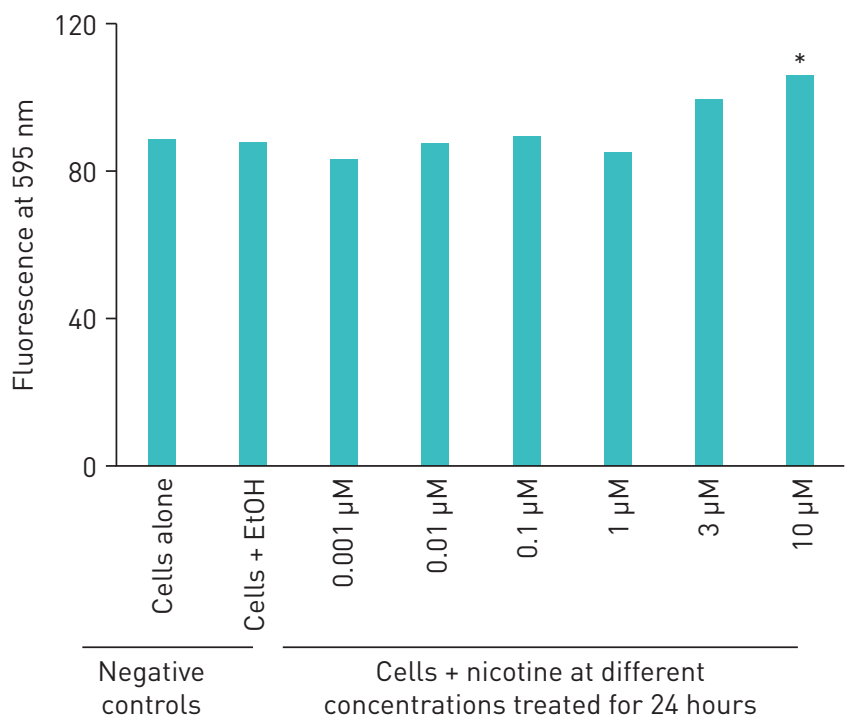




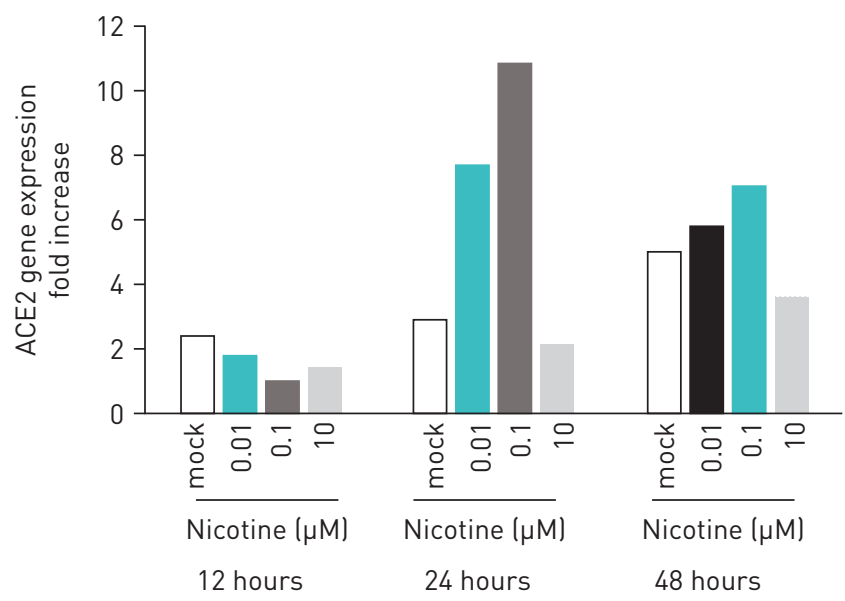

FIGURE 2 Angiotensin converting enzyme 2 (ACE2) gene expression in A549 cells at different times after exposure to different doses of nicotine, measured by real-time PCR. The mock group is represented by cell cultures exposed to the diluent alone in which the nicotine was solubilised. Differences in ACE2 expression are represented as the fold-change in gene expression using the housekeeping gene $\beta$-actin as the internal control for normalisation.

expression. As shown in figure $4 \mathrm{a}$ and $\mathrm{b}$, treatment of cells with nicotine increased both the number and the size of the colonies as well as the migration of A549 cells in a dose-dependent manner; the maximum effect was observed at $0.1 \mu \mathrm{M}$

\section{Nicotine facilitates the in vitro replication of SARS-CoV-2}

Given the results shown above, we examined whether the treatment with nicotine could increase SARS-CoV-2 replication in A549 cell cultures. In these experiments, A549 cell cultures previously exposed for $24 \mathrm{~h}$ to nicotine at the dose of $0.1 \mu \mathrm{M}$ were then infected with two TCID ${ }_{50}$ of SARS-CoV-2. This $\mathrm{TCID}_{50}$ dose was selected according to results from preliminary experiments in which 100, 20 and two TCID $_{50}$ doses were tested. Two TCID 50 of SARS-CoV-2 was the optimal dose for investigating differences in virus replication on A549 cell cultures. No or slight differences were observed when 100 and 20 TCID $_{50}$ doses were used, respectively. The increase in ACE2 expression induced an increased SARS-CoV-2 replication as detected by quantitative real-time PCR targeting three different viral genes (figure 5), and by an immunofluorescent assay for viral proteins (figure 6), which revealed an increased cytopathic effect (figure 7).

\section{Discussion}

In this work, we report data supporting our initial hypothesis that nicotine may be the "hidden" link of SARS-CoV-2 infection [23]. Specifically, our data show that nicotine: i) enhances the expression levels of $\alpha 7-n A C h R$ in A549 human adenocarcinoma cell line; ii) is not cytotoxic and induces cell proliferation, as well as cell migration; iii) up-regulates ACE2 expression; iv) increases SARS-CoV-2 replication; v) increases the transcription of SARS-CoV-2 viral proteins; and vi) increases SARS-CoV-2 cytopathic effect. These results address our research question and robustly support the hypothesis that there is a causal link between exposure to nicotine and the involvement and severity of COVID-19 infection. The concentration of nicotine in all the experiments is principally $0.1 \mu \mathrm{M}$, cells are treated both after a short time $(1 \mathrm{~h})$ and for a longer time $(24-48 \mathrm{~h})$ mimicking the human exposure in smokers. The percentage of nicotine in one tobacco cigarette is approximately $1-2 \%=1-2 \mathrm{~g} \cdot 100^{-1}$. Considering a human body weight average equal to $68 \mathrm{~kg}$ one cigarette may deliver approximately $10-30 \mu \mathrm{g} \cdot \mathrm{kg}^{-1}$, resulting in a peak plasma level of 10-50 ng. $\mathrm{mL}^{-1}$. A concentration equal to $50 \mathrm{ng} \cdot \mathrm{mL}^{-1}$ can be converted to molarity dividing by nicotine molecular weight (i.e. 162) $\left(50 \mathrm{ng} \cdot \mathrm{mL}^{-1}\right.$ divided by 162$)=0.309=3.1 \times 10^{-7} \mathrm{M}$ [37].

To the best of our knowledge, this is the first work that directly shows the effect of nicotine on SARS-CoV-2 infection. Nicotine may affect different processes in A549 cells, such as growth, invasion, and metastasis, epithelial-mesenchymal transition (EMT), induction of angiogenesis factor, inhibition of drug-induced apoptosis, reduction of p53, and phosphop53 [24, 26]. Importantly, nicotine in A549 cells, as well as in human unaffected bronchial epithelial cells $[21,23]$ enhances the expression of ACE2 both as mRNA and as proteins. Physiologically, ACE2, in the renin-angiotensin system (RAS), promotes the degradation of angiotensin II, potent vasoconstriction, pro-inflammatory, and pro-fibrosis agent, converting angiotensin II into angiotensin(1-7), a vasodilating, anti-proliferative and apoptotic agent [38] 
a)

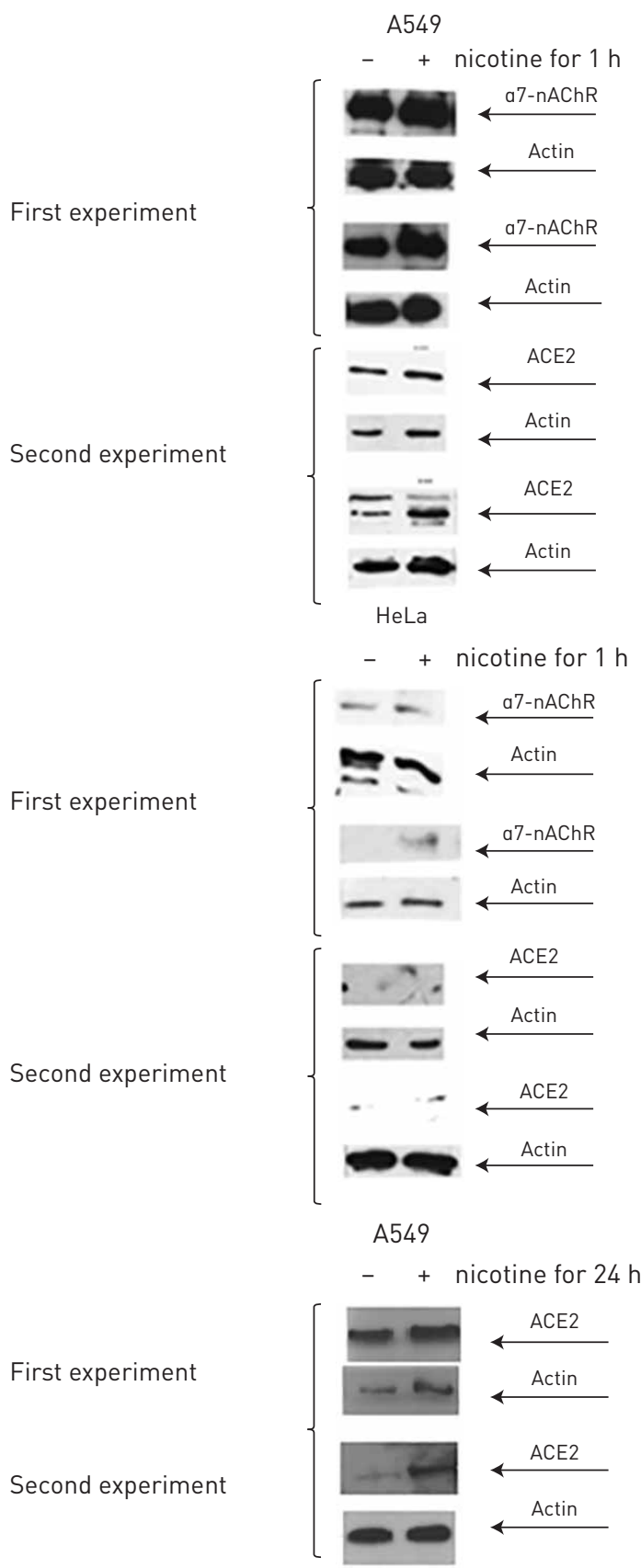

b)

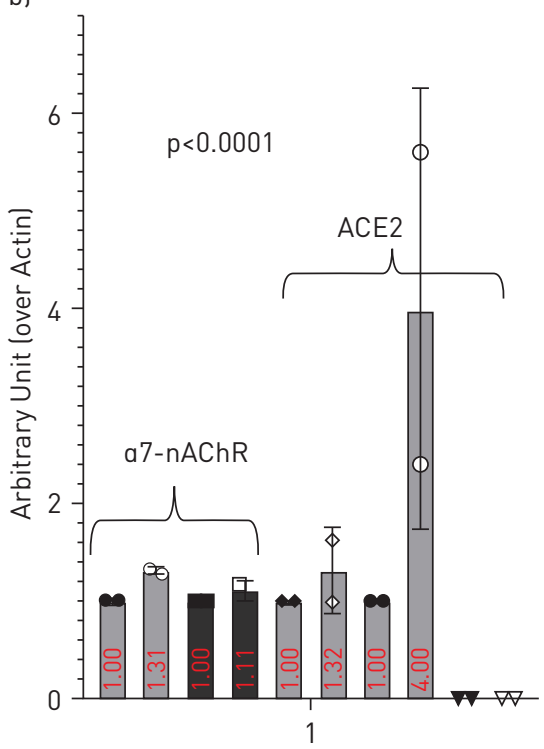

c)
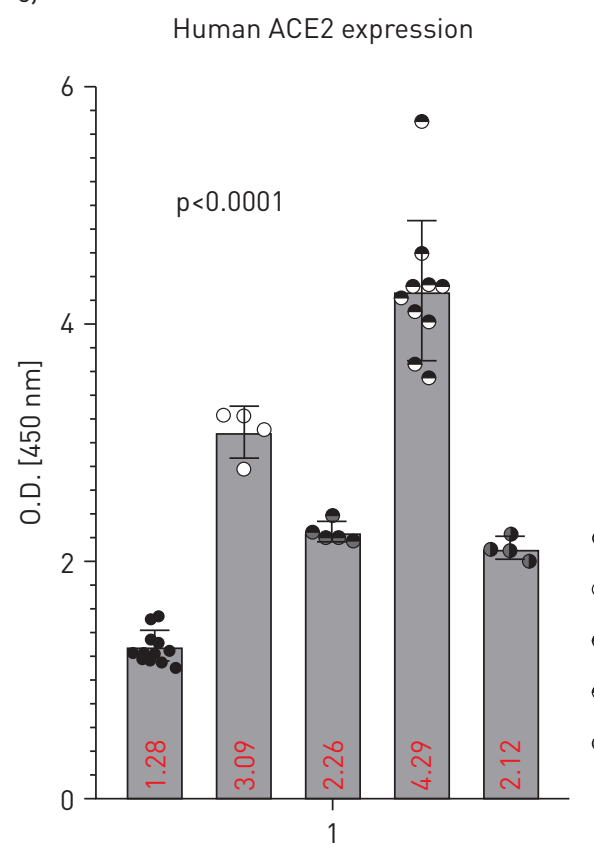

- A549 a7-nAChR: CTRL 1 h

O A549 a7-nAChR: Nicotine $1 \mathrm{~h}$

- HeLa a7-nAChR: CTRL $1 \mathrm{~h}$

$\square$ HeLa a7-nAChR: Nicotine $1 \mathrm{~h}$

- A549 ACE2: CTRL $1 \mathrm{~h}$

$\diamond$ A549 ACE2: Nicotine $1 \mathrm{~h}$

- A549 ACE2: CTRL $24 \mathrm{~h}$

O A549 ACE2: Nicotine $24 \mathrm{~h}$

จ HeLa ACE2: CTRL 1 h

$\nabla$ HeLa ACE2: Nicotine $1 \mathrm{~h}$

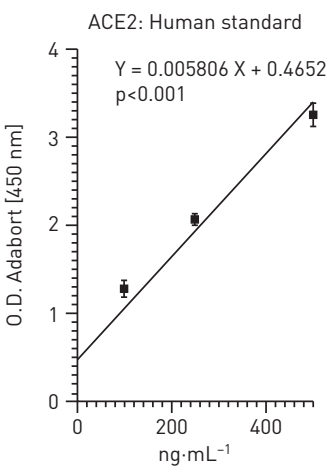

○ A549: CTRL

o A549: Nicotine $0.01 \mu \mathrm{M} 24 \mathrm{~h}$

- A549: Nicotine $0.1 \mu \mathrm{M} 1 \mathrm{~h}$

- A549: Nicotine $0.1 \mu \mathrm{M} 24 \mathrm{~h}$

- A549: Nicotine $0.1 \mu \mathrm{M} 48 \mathrm{~h}$

FIGURE 3 Quantitative levels of nicotinic receptor (nAChR) sub-type $\alpha 7$ and angiotensin converting enzyme 2 (ACE2) proteins in extracts of A549 and HeLa cells exposed to nicotine for 1 or $24 \mathrm{~h}$ at $0.1 \mu \mathrm{M}$ using Western blot analysis (a and b: densitometric analysis). Results of two different experiments are reported. All data are expressed as mean \pm SD of three independent experiments. cl Quantitative levels of ACE2 proteins in A549 cells exposed to $0.01 \mu \mathrm{M}$ for $24 \mathrm{~h}$ or $0.1 \mu \mathrm{M}$ for 1,24 , or $48 \mathrm{~h}$ evaluated by sandwich ELISA. Regression equation linearity for ACE2 human standard was performed with Prism. All data are expressed as mean \pm SD of two independent experiments performed in triplicate. Statistical significance was analysed with one-way ANOVA with multiple-comparison and post hoc test with Bonferroni correction. Experiments were performed at least two times in triplicate.

ACE2 is the only well-recognised functional receptor of SARS-CoV-2, that allows viral entry into human cells $[20,36,38]$. A specific region of SARS-CoV-2, namely spike protein (S1), interacts with ACE2 and, in cooperation with host proteases, mainly transmembrane serine protease 2 (TMPRSS2), promotes cellular entry into host cells. Various experiments support the role of ACE2 in the entry of SARS-CoV-2, thus antibodies against ACE2 block the SARS-CoV-2 infection [38], while expression of ACE2 in refractory cell 
a) Anchorage-independent growth

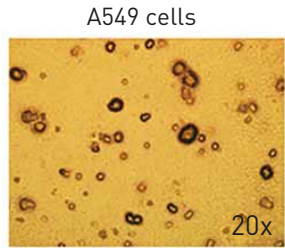

A549 cells: Nicotine $0.1 \mu \mathrm{M}$
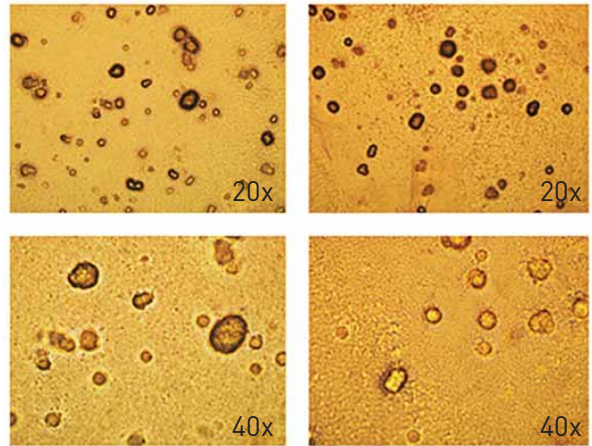

b)

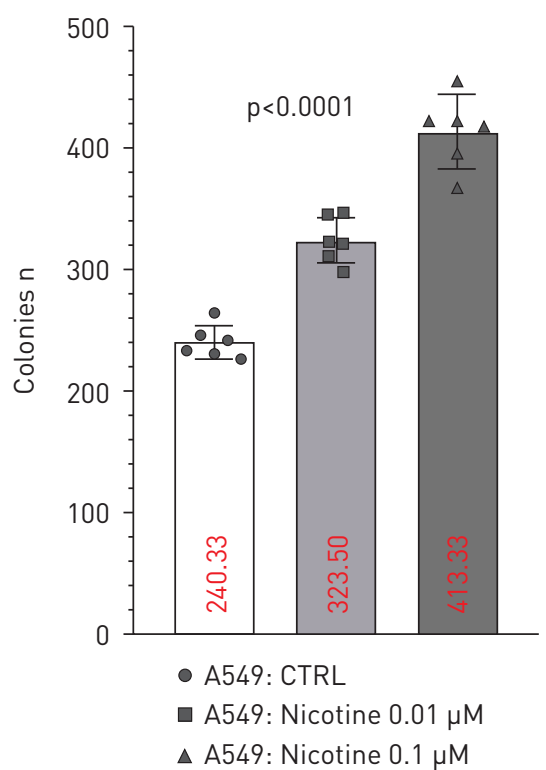

c) Cell migration

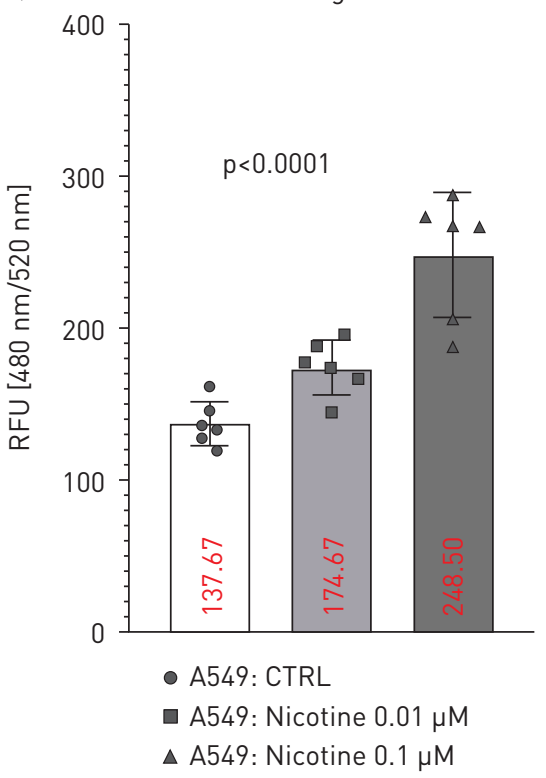

FIGURE 4 a) Anchorage-independent growth. Effects of treatment with nicotine 0.01 or $0.1 \mu \mathrm{M}$ on A549 cells. a) Colony formation. Magnification 20x or 40x. b) Cell migration. 30000 A549 cells were plated and treated with different concentrations of nicotine 0.01 or $0.1 \mu \mathrm{M}$ for $24 \mathrm{~h}$. All data are expressed as mean $\pm S D$ of three experiments performed in triplicate. Statistical significance was analysed with one-way ANOVA with multiple-comparison and post hoc test with Bonferroni correction. Experiments are performed at least two times in triplicate.

lines (i.e. HeLa cells) results in SARS-CoV-2 replication [36]. After binding of SARS-CoV-2 to ACE2, the membrane fusion and virus entry inside the cell, ACE2 is down-regulated thus the degradation of Ang II is attenuated or blocked. The comprehensive understanding of the mechanisms involved in the nicotine upregulation of ACE2 pulmonary expression is still unknown. Among these, there is a possible role of $\mathrm{nAChR}$, engaged by nicotine. We have recently shown that nicotine, through activation of $\alpha 7-\mathrm{nAChR}$, increases the expression level of ACE2 in unaffected human bronchial epithelial cells (HBEpC) inducing phospho-S6 ribosomal protein (Ser235/236), Akt1, phospho-Akt (Ser473 and Thr308) and phospho-p44/ 42 MAPK (Thr202/Tyr204) [23, 24]. No increase of ACE2 is observed in si-mRNA- $\alpha 7-H B E p C$ or the presence of $\alpha$-bungarotoxin, an $\alpha 7$ nicotine antagonist, suggesting that the increase of ACE2 is specifically mediated by $\alpha 7-\mathrm{nAChR}[23,24]$. Very recently, LeUNG et al. [21], in a cohort of 42 subjects reveal evidence in support of this hypothesis finding that CHRNA7, encoding $\alpha 7-\mathrm{nAChR}$, expression in airway epithelial cells is significantly correlated with the expression of ACE2. CHRNA7 expression is higher in COPD than in non-COPD patients with a trend in the direction of higher expression in current smokers compared to former and never smokers. CAI et al. [39] reported higher ACE2 gene expression in former smokers' lungs compared with non-smokers' lungs. Also, they found higher ACE2 gene expression in Asian current smokers compared with non-smokers but not in Caucasian current smokers, which may indicate the presence of a gene-smoking interaction. Also, they found that the ACE2 gene is expressed in specific cell 
FIGURE 5 Cycle threshold analysis of three different PCR targets $(E$, $R d R p$ and $N$ genes) of the severe acute respiratory syndrome coronavirus 2 (SARS-CoV-2) genome in the supernatants of A549 cells previously exposed to nicotine.

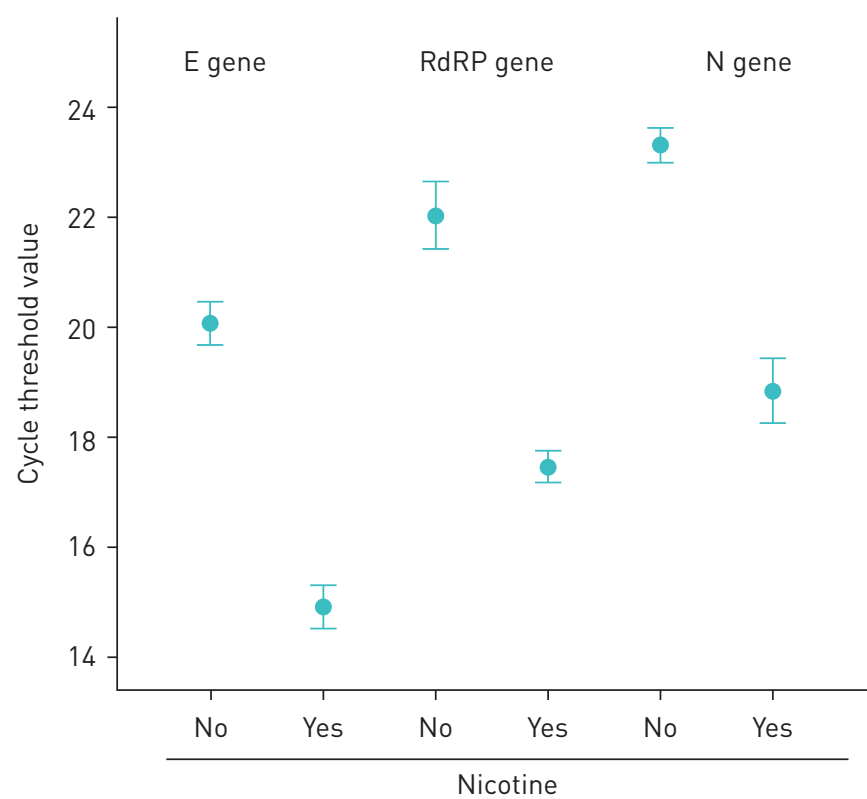

types related to smoking history and location. In bronchial epithelium, ACE2 is actively expressed in the goblet cells of current smokers and club cells of non-smokers. In alveoli, ACE2 is actively expressed in remodelled AT2 cells of former smokers [39]. Accordingly, sub-chronic e-cigarette exposure with nicotine increased inflammatory cellular influx of macrophages and T-lymphocytes in mice, including increased pro-inflammatory cytokines in bronchoalveolar lavage and increased SARS-CoV-2 ACE2 receptor, whereas nAChR $\alpha 7 \mathrm{KO}$ mice show reduced inflammatory responses associated with decreased ACE2 receptor [40].
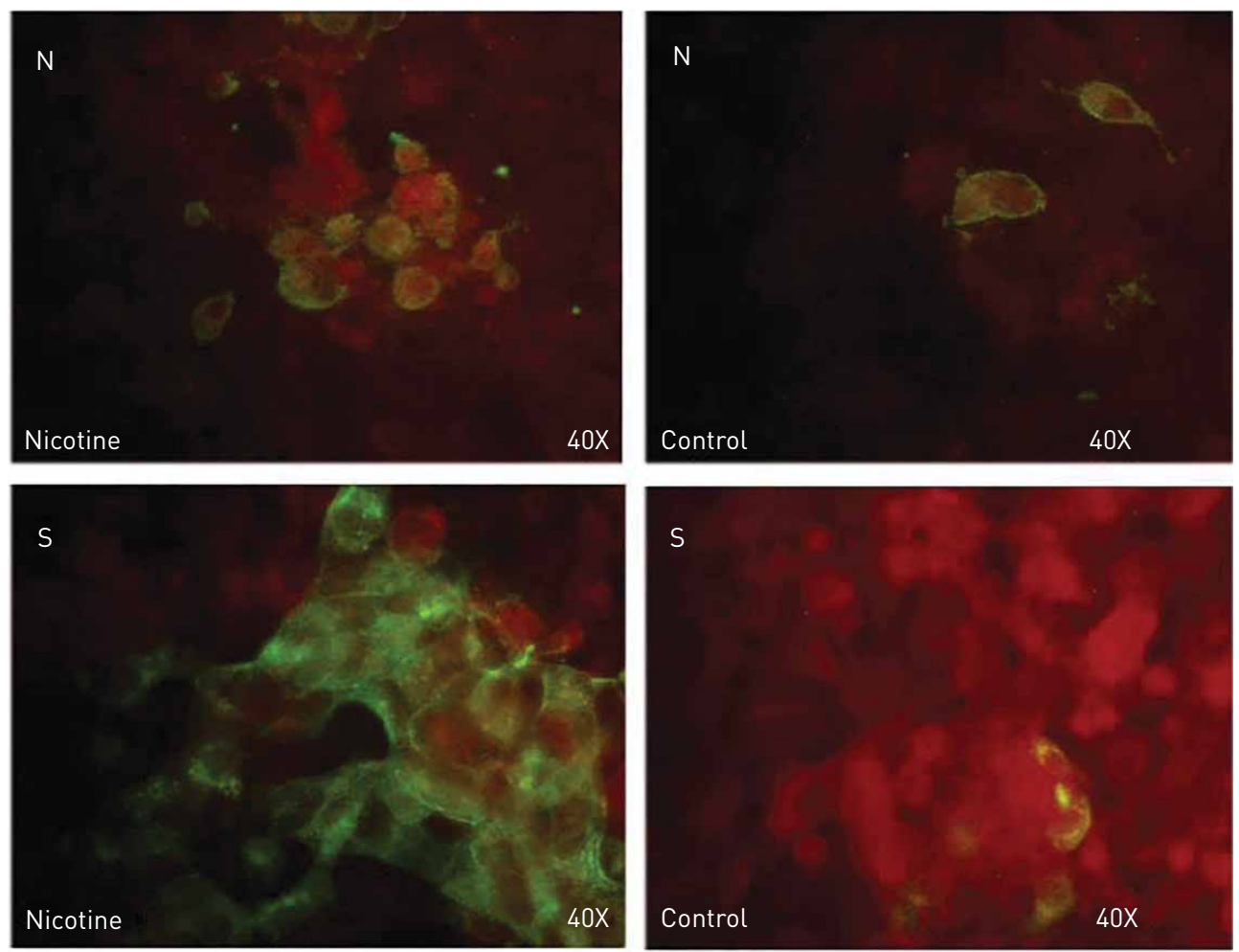

FIGURE 6 Immunofluorescence assay for SARS-CoV-2 $\mathrm{S}$ and $\mathrm{N}$ proteins before or after challenge with nicotine. 

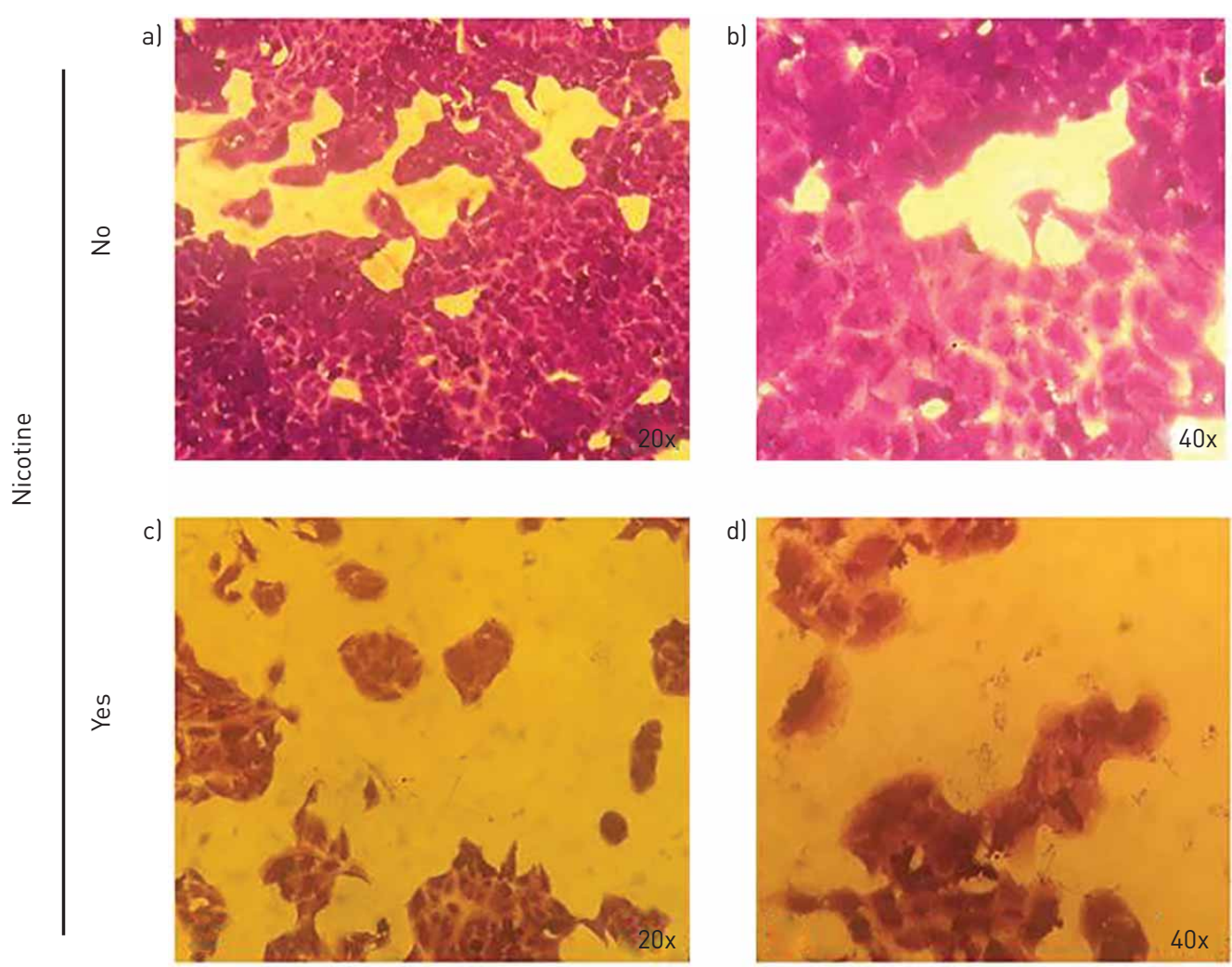

FIGURE 7 Increase in the cytopathic effect of SARS-CoV-2 on A549 cells previously exposed to nicotine. More than $70 \%$ increase in cell mortality is observed.

LEE et al. [41] reported, previously, that cigarette smoking, but not vaping, up-regulates ACE2. We show here instead, that nicotine (and hence potentially any nicotine-delivering habit) can up-regulate ACE2 expression in pneumocytes.

Nevertheless, some publications maintain that nicotine may be a protective factor against COVID-19 infection [4]. Specifically, Changeux et al. [42] hypothesised that the nAChR may be the target for the prevention and control of COVID-19 infection. The authors conclude their paper by noting 'under controlled settings, nicotinic agents could provide an efficient treatment for an acute infection such as Covid-19". This assertion is the base of the so-called 'Nicotinic Hypothesis' [42]. Changeux et al. [42] do not accept the generally well-confirmed finding that SARS-CoV-2 enters human cells through ACE2 and, in turn, does not agree that nicotine up-regulates ACE2 expression. Thus CHAngeux et al. [42] claim that $\alpha 7-n A C h R$ may play a key role in SARS-CoV-2 infection, being the receptor of SARS-CoV-2, and consequently argue that nicotine may compete with or even block the binding of SARS-CoV-2 to nAChR. Indeed, according to this hypothetical mechanism, nicotine may reduce smokers' chance of infection. This hypothesis, although captivating, until now is not supported by any experimental data. However, it has been shown with in silico experiments that the SARS-CoV-2 S protein binds to $\alpha 7-\mathrm{nAChR}$ [9] or with both $\alpha 7$ - and $\alpha 9-\mathrm{nAChR}$ [8]. These findings are not verified in vivo and in vitro. Specifically, SARS-CoV-2 has not been reported yet to open the nAChR channel and to allow the entry of $\mathrm{Ca}^{2+}$ inside a cell, as well-known for acetylcholine and nicotine [26]. Moreover, no SARS-CoV-2 binding to nAChR is studied in acetylcholine binding protein (AChBP) crystal structures. Our data, summarised in figure 8, show that in the presence of nicotine, when $\alpha 7-\mathrm{nAChR}$ are upregulated and engaged (i.e. ERK and MAPK activation), ACE2 is expressed more and, in turn, the infection property of SARS-CoV-2 is increased. A549 cell line is broadly utilised as a model of type II pulmonary epithelial cell; however, these cells are incompatible with SARS-CoV-2 infection and need ACE2 transfection to become permissive to virus infection [43]. In our experiments, we show that nicotine converts A549 cells to a permissive state for SARS-CoV-2 infection. We hypothesise that this conversion is linked to an increased expression of ACE2. However, it is possible that other co-receptors possibly stimulated by nicotine may be involved. It has been known that nicotine not only increases cell proliferation (this work and reviewed in [26]) but prevents or delays cell death [24] generating more functional cells available for a possible viral infection. Thus, 


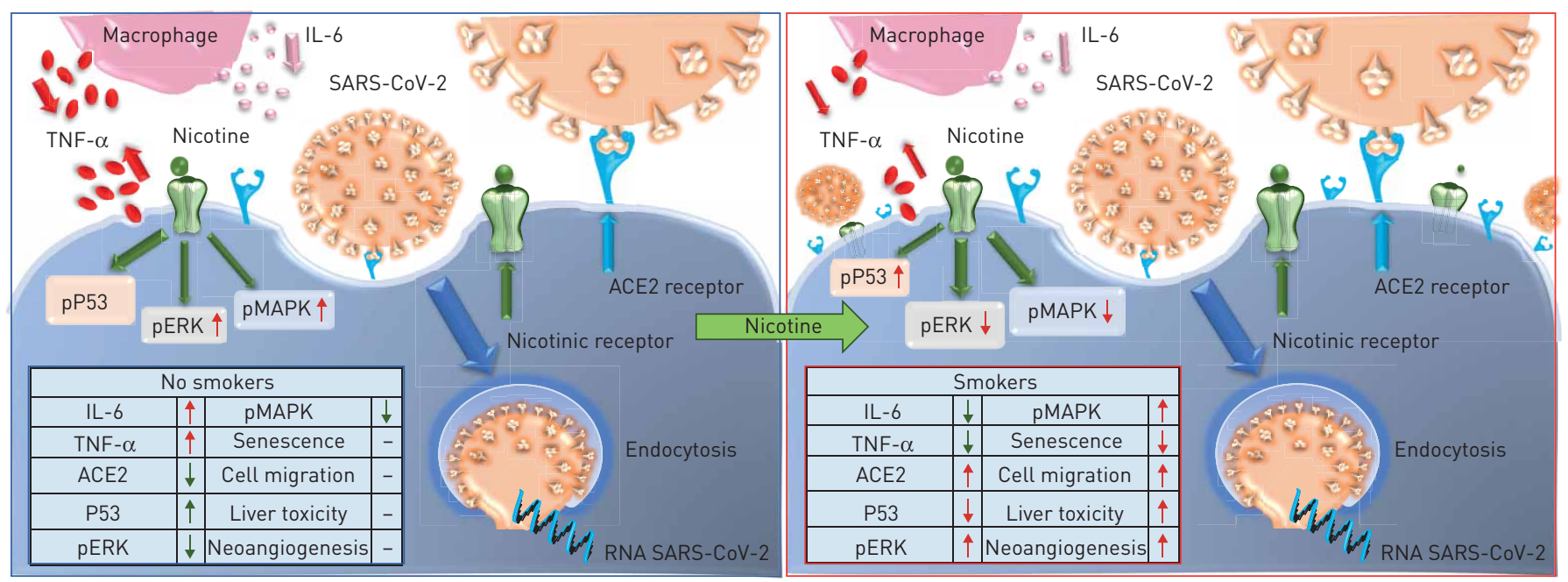

FIGURE 8 A schematic model for how nicotine exposure may work on the risk of COVID-19. On the left in non-smokers (not exposed to nicotine). On the right in smokers exposed to nicotine.

SARS-CoV-2 speedily replicates in actively transcriptional cells [44] requiring the availability of cellular nucleotide pools [45], and in turn of proliferating and viable cells.

It has been reported that the so-called "cytokine storm" is associated with COVID-19 severity and is an important cause of COVID-19 death [46]. Indeed, intracellular SARS-CoV-2 triggers a strong immune response accompanied by inflammatory cytokine production (i.e. tumour necrosis factor (TNF) $\alpha$ and interleukin (IL)-6) [46]. Literature data report that nicotine reduces the release of TNF- $\alpha$ and IL- 6 after cell stimulation with LPS in human bronchial epithelial cells [47]. Experiments were conducted on 12 adult male normal subjects, of which six received overnight transcutaneous nicotine administration by application of a standard patch $(7 \mathrm{mg})$ and then $6 \mathrm{~h}$ later, all subjects were given an intravenous dose of endotoxin $\left(2 \mathrm{ng} \cdot \mathrm{kg}^{-1}\right)$. After an additional $24 \mathrm{~h}$, all subjects were evaluated for cytokines expression. No significant differences in the circulating TNF- $\alpha$, IL6 and IL8 levels between the nicotine and placebo groups [48]. We induced cytokines production, for the first time in human unaffected cells, i.e. HBEpC, using polyinosinic-polycytidylic acid (poly(I:C)), a synthetic analogue of double-stranded RNA (dsRNA), which mimics viral infection and induces antiviral immune responses by promoting the production of both Type I Interferon and inflammatory cytokines such as TNF- $\alpha$ and IL6. Nicotine reduces the amount of TNF- $\alpha(-37.3 \%)$ and IL-6 (-29.3\%) in these cells [24]. These data suggest that the reduction of cytokines by nicotine is not very strong and question its use to control the cytokine storm.

Several epidemiological surveys have been published or are available as pre-print. Evidence from these studies is somehow contrasting, and the role of tobacco smoking, NRT or vaping is still to be assessed [4-6, 49-56]. In many cases, the presence of underreporting in recording smoking history at admission, especially to ICU during the COVID-19 outbreak, when the hospitals are overwhelmed, cannot be ruled out. To clarify the role of tobacco smoking on COVID-19 severity and progression, a longitudinal observational study titled COvid19 and SMOking in Italy (COSMO-IT) was designed [57]. One of the objectives of the study is to quantify the role of tobacco smoking and smoking cessation on the severity and progression of COVID-19 in hospitalised patients.

Nicotine exposure, through different types of smoking habits, sustains cellular and molecular mechanisms for SARS-CoV-2 susceptibility and severity throughout the infection in the lungs as well as in other organ systems expressing both $\alpha 7-\mathrm{nAChR}$ and ACE2 (i.e. neurons, enterocytes). Together, our data help to better understand and characterise the connections between airway epithelial ACE- 2 , and $\alpha 7-\mathrm{nAChR}$, and the development of severe COVID-19. In the light of present results caution shall be applied in trials utilising nicotine to prevent or treat COVID-19.

Acknowledgments: We would like to acknowledge Leonardo Lupacchini from the IRCCS San Raffaele Pisana for densitometric analysis.

Conflict of interest: None declared. 
Support statement: This work was partially supported by "Ricerca Corrente" to P. Russo awarded by the Italian Ministry of Health. Funding information for this article has been deposited with the Crossref Funder Registry.

\section{References}

1 Ou M, Zhu J, Ji P, et al. Risk factors of severe cases with COVID-19: a meta-analysis. Epidemiol Infect 2020; 148: e175.

2 Zhao J, Li X, Gao Y, et al. Risk factors for the exacerbation of patients with 2019 Novel Coronavirus: A meta-analysis. Int J Med Sci 2020; 17: 1744-1750.

3 Fillmore NR, La J, Szalat RE, et al. Prevalence and outcome of Covid-19 infection in cancer patients: a national Veterans affairs study. J Natl Cancer Inst 2020: in press [https://doi.org/10.1093/jnci/djaa159].

4 Farsalinos K, Barbouni A, Niaura R. Systematic review of the prevalence of current smoking among hospitalized COVID-19 patients in China: could nicotine be a therapeutic option? Intern Emerg Med 2020; 15: 845-852.

5 Israel A, Feldhamer I, Lahad A, et al. Smoking and the risk of COVID-19 in a large observational population study. MedRxiv 2020; preprint [https://doi.org/10.1101/2020.06.01.20118877].

6 Miyara M, Tubach F, Martinez V, et al. Low rate of daily smokers in patients with symptomatic COVID-19. MedRxiv 2020; preprint [https://doi.org/10.1101/2020.06.10.20127514].

7 Farsalinos K, Eliopoulos E, Leonidas DD, et al. Nicotinic cholinergic system and COVID-19: In silico identification of an interaction between SARS-CoV-2 and nicotinic receptors with potential therapeutic targeting implications. Intern J Mol Sci 2020; 21: 5807.

8 Oliveira ASF, Ibarra AA, Bermudez I, et al. Simulations support the interaction of the SARS-CoV-2 spike protein with nicotinic acetylcholine receptors and suggest subtype specificity. bioRxiv 2020; preprint [https://doi.org/10 $1101 / 2020.07 .16 .206680]$.

9 Hasanagic S, Serdarevic F. Potential role of memantine in the prevention and treatment of COVID-19: its antagonism of nicotinic acetylcholine receptors and beyond. Eur Respir J 2020; 56: 2001610.

10 Leung JM, Yang CX, Sin DD. COVID-19 and nicotine as a mediator of ACE-2. Eur Respir J 2020; 55: 2001261.

11 Tizabi Y, Getachew B, Copeland RL, et al. Nicotine, and the nicotinic cholinergic system in COVID-19. FEBS J 2020; 287: 3656-3663.

12 González-Marrón A, Martínez-Sánchez JM. Correlation between the prevalence of tobacco smoking and risk and severity of COVID-19 at the national level in the European Union: an ecological study. MedRxiv 2020; preprint [https://doi.org/10.1101/2020.04.28.20083352].

13 Norden MJ, Avery DH, Norden JG, et al. National smoking rates correlate inversely with COVID-19 mortality. MedRxiv 2020; preprint [https://doi.org/10.1101/2020.06.12.20129825].

14 Olds JL, Kabbani N. Is nicotine exposure linked to cardiopulmonary vulnerability to COVID-19 in the general population? FEBS J 2020; 287: 3651-3655.

15 Ahmed N, Maqsood A, Abduljabbar T, et al. Tobacco smoking a potential risk factor in transmission of COVID-19 infection. Pak J Med Sci 2020; 36: S104-S107.

16 Gulsen A, Arpinar Yigitbas B, Uslu B, et al. The effect of smoking on COVID-19 symptom severity: Systematic review and meta-analysis. Pulmonary Med 2020; 2020: in press [https://doi.org/10.1155/2020/7590207].

17 Dorjee K, Kim H. Epidemiological risk factors associated with death and severe disease in patients suffering from COVID-19: a comprehensive systematic review and meta-analysis. MedRxiv 2020; preprint [https://doi.org/10. 1101/2020.06.19.20135483].

18 Cattaruzza MS, Zagà V, Gallus S, et al. Tobacco smoking and COVID-19 pandemic: old and new issues. A summary of the evidence from the scientific literature. Acta Biomed 2020; 91: 106-112.

19 Gallus S, Lugo A, Gorini G. No double-edged sword and no doubt about the relation between smoking and COVID-19 severity. Eur J Intern Med 2020; 77: 33-35.

20 Wang Q, Zhang Y, Wu L, et al. Structural and functional basis of SARS-CoV-2 entry by using human ACE2. Cell 2020; 181: 894-904.

21 Leung JM, Yang CX, Tam A, et al. ACE-2 expression in the small airway epithelia of smokers and COPD patients: implications for COVID-19. Eur Respir J 2020; 55: 2000688.

22 Brake SJ, Barnsley K, Lu W, et al. Smoking upregulates angiotensin-converting enzyme-2 receptor: a potential adhesion site for novel coronavirus SARS-CoV-2 (Covid-19). J Clin Med 2020; 9: 841

23 Russo P, Bonassi S, Giacconi R, et al. COVID-19 and smoking: is nicotine the hidden link? Eur Respir J 2020; 55 2001116.

24 Lupacchini L, Maggi F, Tomino C, et al. 2020. Nicotine changes airway epithelial phenotype and may increase the SARS-COV-2 infection severity. Molecules 2021; 26: 101

25 Cirillo P, De Rosa S, Pacileo M, et al. Nicotine induces tissue factor expression in cultured endothelial and smooth muscle cells. J Thromb Haemost 2006; 4: 453-458.

26 Cardinale A, Nastrucci C, Cesario A, et al. Nicotine: specific role in angiogenesis, proliferation, and apoptosis. Crit Rev Toxicol 2012; 42: 68-89.

27 Irfan A, Li Y, Bhatnagar A, et al. Association between serum cotinine levels and electrocardiographic left atrial abnormality. Ann Noninvasive Electrocardiol 2019; 24: e12586.

28 Ackermann M, Verleden SE, Kuehnel M, et al. Pulmonary vascular endothelialitis, thrombosis, and angiogenesis in Covid-19. N Engl J Med 2020; 383: 120-128.

29 Razani-Boroujerdi S, Singh SP, Knall C, et al. Chronic nicotine inhibits inflammation and promotes influenza infection. Cell Immunol 2004; 230: 1-9.

30 Oakes JM, Fuchs RM, Gardner JD, et al. Nicotine and the renin-angiotensin system. Am J Physiol Reg Integr Comp Physiol 2018; 315: R895-R906.

31 Voinsky I, Gurwitz D. Smoking and COVID-19: Similar bronchial ACE2 and TMPRSS2 expression and higher TMPRSS4 expression in current versus never smokers. Drug Dev Res 2020; 81: 1073-1080.

32 Dhillon P, Breuer M, Hirst N. COVID-19 breakthroughs: separating fact from fiction. FEBS J 2020; 287: $3612-3632$.

33 Jacobs M, Van Eeckhoutte HP, Wijnant SR, et al. Increased expression of ACE2, the SARS-CoV-2 entry receptor, in alveolar and bronchial epithelium of smokers and COPD subjects. Eur Respir J 2020; 56: 2002378. 
34 Maremanda KP, Sundar IK, Li D, et al. Age-dependent assessment of genes involved in cellular senescence, telomere, and mitochondrial pathways in human lung tissue of smokers, COPD and IPF: Associations with SARS-CoV-2 COVID-19 ACE2-TMPRSS2-Furin-DPP4 axis. Front Pharmacol 2020; 11: 584637.

35 Giard DJ, Aaronson SA, Todaro GJ, et al. In vitro cultivation of human tumors: establishment of cell lines derived from a series of solid tumors. J Natl Cancer Inst 1973; 51: 1417-1423.

36 Zhou P, Yang XL, Wang XG, et al. A pneumonia outbreak associated with a new coronavirus of probable bat origin. Nature 2020; 579: 270-273.

37 Matta SG, Balfour DJ, Benowitz NL, et al. Guidelines on nicotine dose selection for in vivo research. Psychopharmacol 2007; 190: 269-319.

38 Li W, Moore MJ, Vasilieva N, et al. Angiotensin-converting enzyme 2 is a functional receptor for the SARS coronavirus. Nature 2003; 426: 450-454.

39 Cai G. Bulk and single-cell transcriptomics identify tobacco-use disparity in lung gene expression of ACE2, the receptor of 2019-nCov. Preprints 2020; preprint [https://doi.org/10.20944/preprints202002.0051.v2]

40 Wang Q, Sundar IK, Li D, et al. E-cigarette-induced pulmonary inflammation and dysregulated repair are mediated by $n A C h R ~ \alpha 7$ receptor: role of nAChR $\alpha 7$ in SARS-CoV-2 Covid-19 ACE2 receptor regulation. Respir Res 2020; 21: 154.

41 Lee AC, Chakladar J, Li WT, et al. Tobacco, but not nicotine and flavor-less electronic cigarettes, induces ACE2, and immune dysregulation. Intern J Mol Sci 2020; 21: 5513.

42 Changeux JP, Amoura Z, Rey FA, et al. A nicotinic hypothesis for Covid-19 with preventive and therapeutic implications. C R Biol 2020; 343: 33-39.

43 Yang J, Petitjean SJL, Koehler M, et al. Molecular interaction and inhibition of SARS-CoV-2 binding to the ACE2 receptor. Nat Commun 2020; 11: 4541.

44 Bojkova D, Klann K, Koch B, et al. Proteomics of SARS-CoV-2-infected host cells reveals therapy targets. Nature 2020; 583: 469-472.

45 Pruijssers AJ, Denison MR. Nucleoside analogues for the treatment of coronavirus infections. Curr Opin Virol 2019; 35: 57-62.

46 Hu B, Huang S, Yin L. The cytokine storm and COVID-19. J Med Virol 2021; 93: 250-256.

$47 \mathrm{Li}$ Q, Zhou XD, Kolosov VP, et al. Nicotine reduces TNF- $\alpha$ expression through an $\alpha 7 \mathrm{nAChR/MyD88/NF-kB}$ pathway in HBE16 airway epithelial cells. Cell Physiol Biochem 2011; 27: 605-612.

48 Wittebole X, Hahm S, Coyle SM, et al. Nicotine exposure alters in vivo human responses to endotoxin. Clin Exp Immunol 2007; 147: 28-34.

49 Zureik M, Baricault B, Vabre C, et al. Nicotine-replacement therapy, as a surrogate of smoking, and the risk of hospitalization with Covid-19 and all-cause mortality: a nationwide, observational cohort study in France. MedRxiv 2020; preprint [https://doi.org/10.1101/2020.07.28.20160630].

50 Tattan-Birch H, Perski O, Jackson SE, et al. COVID-19, smoking, vaping and quitting: a representative population survey in England. Addiction 2020; in press [https://doi.org/10.1111/add.15251].

51 Vardavas CI, Nikitara K. COVID-19 and smoking: A systematic review of the evidence. Tob Induc Dis 2020; 20: 20.

52 Berlin I, Thomas D, Le Faou AL, et al. COVID-19 and smoking. Nicotine Tob Res 2020; 22: 1650-1652.

53 Zhao Q, Meng M, Kumar R, et al. The impact of COPD and smoking history on the severity of COVID-19: A systemic review and meta-analysis. J Med Virol 2020; 92: 1915-1921.

54 van Zyl-Smit RN, Richards G, Leone FT. Tobacco smoking and COVID-19 infection. Lancet Respir Med 2020; 8 664-665.

55 Alqahtani JS, Oyelade T, Aldhahir AM, et al. Prevalence, severity and mortality associated with COPD and smoking in patients with COVID-19: a rapid systematic review and meta-analysis. PLoS One 2020; 15: e0233147.

56 Tsigaris P, Teixeira da Silva JA. Smoking prevalence and COVID-19 in Europe. Nicotine Tob Res 2020; 22: $1646-1649$.

57 Cattaruzza MS, Gorini G, Bosetti C, et al. Covid-19 and the role of smoking: the protocol of the multicentric prospective study COSMO-IT (COvid19 and SMOking in ITaly). Acta Biomed 2020; 91: e2020062. 